Natiol (NASA-News-Belease-80-62) EXPERIAENTS

Spac SELECTED FOR FIRST SPACELAB FLIGHT (National

N $80-73606$

Wash

Aeronautics and Space Administration): 7 p

$\mathrm{AC} 2$

$00 / 12 \quad 18704$

Nicholas Panagakos

Headquarters, Washington, D.C.

(Phone: 202/755-3680)

For Release

IMMEDIATE

John B. Taylor

Marshall space Flight Center, Huntsville, Ala.

(Phone: 205/453-0034)

RELEASE NO: $80-62$

\title{
EXPERIMENTS SELECTED FOR FIRST SPACELAB FLIGHT
}

NASA and the European Space Agency have selected 37 scientific experiments to be conducted on the first flight of Spacelab, scheduled for launch aboard the space shuttle in late 1982 .

The experiments fall into five broad categories: atmospheric physics and Earth observations, space plasma physics, material sciences and technology, astronomy and solar physics, and the life sciences. Thirteen are sponsored by NASA; the remainder are the responsibility of the European Space Agency, a consortium of 11 nations. (Member nations of the European Space Agency are Belgium, Denmark, France, West Germany, Ireland, Italy, The Netherlands, Spain, Sweden, Switzerland 7 क क the United Kingdom.

$$
\text { -more- }
$$


Dr. Thomas A. Mutch, NASA Associate Administrator for Space Science, announced selection of the NASA-sponsored experiments in letters to the experiment developers, who are called Principal Investigators.

The selection was made from a list of experiments identified several years ago for definition and development. Three NASA-sponsored experiments and a major European Space Agency facility that were under development had to be deferred and will be assigned to subsequent spacelab flights. The major limiting factor that prevented the selection of all experiments under development was mass, according to the Spacelab 1 mission manager. Each agency will be able to fly 1,392 kilograms $(3,062$ pounds $)$ of experiment equipment on the mission.

Spacelab is a flexible laboratory system that can be installed in the cargo bay of the space shuttle orbiter to provide an orbital research center for both astronauts and scientists. Unlike its predecessor, skylab, this new system will not be left in space unattended. It will remain in the Shuttle for the duration of its mission, and be returned to Earth for refurbishment and preparation for the next mission. 
The spacelab facility is being designed and manufactured by the European Space Agency and a European contractor consortium. NASA will furnish the Space Shuttle and will manage the in-orbit activities with support from ESA.

Unique non-astronaut science crew members, called Payload Specialists, will provide'support to the Principal Investigators in conducting their experiments. in space.

Five Payload Specialists, two Americans and three Europeans, are now training for the first mission. Two of this group, an American and a European, will fly aboard Spacelab 1. The other three will provide support to the mission in the Operation Control Center at NASA's Johnson Space Center, Houston.

The Marshall Space Flight Center, Huntsville, Ala., is Spacelab 1 mission manager for NASA.

The NASA experiments selected and the Principal Investigators involved are:

Dr. Marsha R. Torr

University of Michigan, Ann Arbor

An Imaging Spectrometric Observatory

Prof. Tatsuzo Obayashi

University of Tokyo, Japan

Space Experiments with Particle Accelerators

Dr. Stephen B. Mende

Lockheed Palo Alto Research Laboratory, Palo Alto, Calif. Atmospheric Emission Photometric Imaging 
Prof. C. Stuart Bowyer

University of California, Berkeley

Far UV Observations Using the Faust Instrument

Prof. Eugene V. Benton

University of San Francisco, Calif.

HZE Particle Dosimetry

Dr. Frank M. Sulzman

Harvard Medical School, Boston

Characterization of Persisting Circadian Rhythms

Dr. Richard C. Willson

Jet Propulsion Laboratory, Pasadena, Calif.

Active Cavity Radiometer Solar Irradiance Monitor

Dr. Raymond L. Gause and Ann F. Whitaker

Marshall Space Flight Center, Huntsville, Ala.

Dr. Coda H. T. Pan, Shaker Research Corp.,

Ballston Lake, N.Y.

Tribological Experiments in Zero Gravity

Prof. Allan H. Brown

University of Pennsylvania, Philadelphia

Nutation of Helianthus Annuus

Prof. Laurence R. Young

Massachusetts Institute of Technology, Cambridge

Vestibular Experiments

Dr. Carolyn S. Leach

Johnson Space Center, Houston

Influence of space Flight on Erythrokinetics in Man

Dr. Millard F. Reschke

Johnson Space Center

Vestibulo-Spinal Reflex Mechanisms

Prof. Edward W. Voss, Jr.

University of Illinois, Urbana

Effects of Prolonged Weightlessness

The Principal Investigators selected for ESA-sponsored experiments are:

Dr. M. Ackermann

Institut d'Aeronomie Spatiale de Belgique,

Brussels, Belgium

Grille Spectrometer 
Dr. M. Herse

Service d'Aeronomie du CNRS, Verrieres-Ie-Brusson, France Waves in the $\mathrm{OH}$ Emissive Layers

Dr. G. Thuillier

Service d'Aeronomie du CNRS

Measurement of Solar Spectrum from 170-3200 Nanometers

Dr. J-L. Bertaux

Service d'Aeronomie du CNRS

Lyman Alpha Study of Hydrogen and Deuterium

Dr. Klaus wilhelm

Max-Planck-Institut fur Aeronomie,

Katlenburg-Lindau, Germany

Low Energy Electron Flux and Its Reaction to Active Experimentation on Spacelab

Dr. C. Beghin

CRPE/CNET/CNRS, Orleans-Cedex, France

Phenomena Induced by Charged Particle Beams

Dr. D. Crommelynck

Institut Royal Meteorologique de Belique, Brussels

Solar Constant Measurement

Prof. G. Courtes

Laboratoire d'Astronomie Spatiale, Marseille, France Very Wide Field Camera

Dr. R. D. Andresen, ESA/ESTEC/SSD, Noordwijk,

The Netherlands

Spectroscopy in $\mathrm{x}$-ray Astronomy

Dr. R. Beaujean

Institut fur Reine and Angewandte Kernphysik der Universitat Kiel, Germany

Isotopic Stack Measurement of Heavy Cosmic Ray Isotopes

Dr. Helen Ross

University of Stirling, Scotland, United Kingdom

Mass Discrimination During Weightlessness

Dr. K. Kirsch

Physiologisches Institut der Freien Universitat

Berlin, Germany

Measurement of Intrathoraxic Venous Pressure via a Peripheral Vein

Dr. K. Kirsch

Physiologisches Institut der Freien Universitat Berlin Collection of Blood Samples for the Determination of Antidiuretic Hormone, Aldosterone and Other Hormones 
Prof. Dr. H. Bucker

DFVIR Institut fur Flugmedizin, Frankfurt, Germany

Advanced Biostack Experiment

Prof. Aristide Scano

University of Rome, Italy

Ballistocardiographic Research in Weightlessness

Dr. G. Horneck

DFVLR Institut fur Flugmedizin

Microorganisms and Biomolecules in Space Environment

Dr. H-L. Green

Clinical Research Centre, Middlesex, Great Britain

Personal Miniature Electro-physiological Tape Recorder

Dr. Augusto Cogoli

Eidgenosslschue Technische Hochschule, Zurich,

Switzerland

Effect of Weightlessness of Lymphocyte Proliferation

Deutsche Forschungs-und Versuchsanstalt fur luft und Raumfahrt, Cologne-Porz, Germany

(Mr. A. Langner, Project Manager)

Metric Camera

Deutsche Forschungs-und Versuchsanstalt fur Luft und Raumfahrt

(Dr. M. Wahl, Project Manager)

Microwave Remote Sensing Experiment

Prof. Dr. R. von Baumgarten

Johannes Gutenberg Universitat, Mainz, Germany

Effect of Rectilinear Accelerations, Optokinetics and Caloric Stimulations on Human Vestibular Reactions. and Sensations in Space

Deutsche Forschungs-und Versuchsanstalt fur Luft und Raumfahrt

(Mr. H. Steimle, Project Manager)

Material Science Double Rack Facility

Dr. C. Belouet

Laboratoire d'Elecironique et de Physique Appliquee, Limeil, France

Mercury Iodide Growth

Prof. J.F. Nielsen

Technical University of Denmark

Prof. A. Authier

Universite Pierre et Marie Curie, Paris

Organic Crystal Growth/Growth of Manganese Carbonate 